Publishing the Family

$\rightarrow$-2. New Americanists A Series Edited by Donald E. Pease 


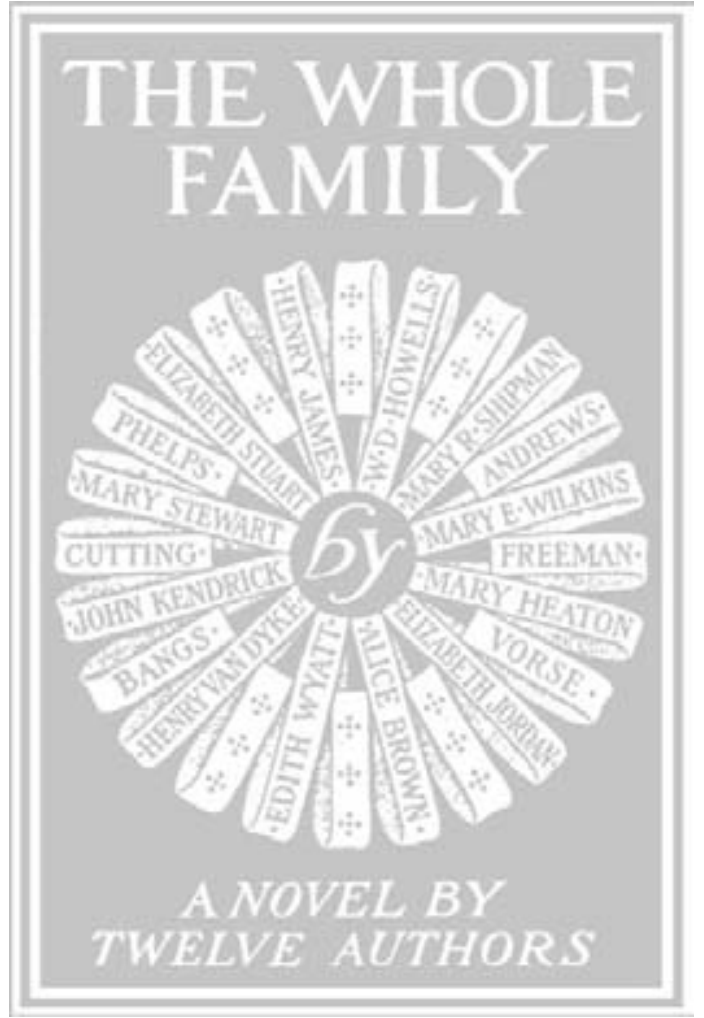


$\rightarrow$ Jone Howard

\section{Publishing the Family}

Duke University Press Durbam \& London $200 I$ 
() 200r Duke University Press All rights reserved

Printed in the United States of America on acid-free paper @

Designed by C. H. Westmoreland

Typeset in Janson by Tseng Information Systems, Inc.

Library of Congress Cataloging-in-Publication Data

appear on the last printed page of this book.

This publication is made possible in part by an award from

the University of Michigan Publication Subvention Program, funded

by the Office of the Vice President for Research, the College of Literature,

Science and the Arts, the International Institute, the English Department, and the Program in American Culture. 
For Jim, Nick, and Alex 
